16 | InterAção

\title{
IMAGENS E NARRATIVAS DA ÁFRICA: DESMISTIFICANDO AS TEORIAS DE RELAÇÕES INTERNACIONAIS ${ }^{1}$
}

\author{
Xaman Korai Minillo²
}

\section{Resumo}

Procura-se questionar as imagens que temos e as narrativas que conhecemos acerca da África e, a partir disso, questionar alguns mitos que construímos acerca do continente no campo das Relações Internacionais. É feita breve levantamento acerca do espaço que o continente tem nas teorias de Relações Internacionais e um questionamento acerca da adequação do panorama com que nos confrontamos, de narrativas incompletas e enviesadas privilegiando um olhar eurocêntrico. Finaliza-se com uma proposta de pluralismo teórico e epistemológico.

\footnotetext{
${ }^{1}$ Texto desenvolvido a partir de palestra na IV Semana Acadêmica de Relações Internacionais da Universidade Federal de Santa Maria - UFSM, novembro de 2013.

2Professora da Universidade Federal da Paraíba - UFPB, email para contato xamankorai@gmail.com.
} 
17 | InterAção

Palavras-chave:África; imagens; narrativas; poder; Teorias de Relações internacionais

\begin{abstract}
The article intends to question the images and narratives we know about Africa and question certain myths we believe in about the continent in the field of International Relations. A brief mapping of the space that the continent occupies in the theories of International Relations is developed and the adequacy of this situation that confronts us, of incomplete and biased narratives that privilege an Eurocentric perspective, is questioned. Finally, the article ends with a proposal for theoretical and epistemological pluralism.
\end{abstract}

Key words: Africa; images; narratives; power; Theory of International Relations 
18 | InterAção

\section{INTRODUÇÃO}

Quando pensamos na África, muitas vezes somos surpreendidos por preconceitos a respeito deste grande continente. Questionando uma plateia de estudantes de graduação de Relações Internacionais a respeito das primeiras coisas que pensam quando se fala em África, as respostas versam sobre $\mathrm{HIV} / \mathrm{AIDS}$, fome, pobreza, miséria, apartheid e conflitos étnicos. Quando buscamos a palavra "África" no site de buscas Google, as imagens que emergem ilustram cenas de pôr-do-sol em safáris, crianças desnutridas e com roupas tradicionais e, com teor político mais óbvio, uma gravura de Cecil Rhodes com os pés sobre o continente africano.

Projeções em mapas também não contribuem para que compreendamos a grandeza do continente africano: a projeção de Mercator, modelo de Mapa Mundi mais conhecido e difundido, assim como qualquer projeção do globo terrestre em um plano, ela cria algumas distorções. Esta projeção, em particular, apresenta uma geometria irreal, 
19 | InterAção

alterando as dimensões das diferentes áreas do globo. Um exemplo disso é o tamanho do continente africano (com mais de 30 milhões de $\mathrm{km}^{2}$ ), que se assemelha em área à Groenlândia (com cerca de 2 milhões de $\mathrm{km}^{2}$ )! Ao mesmo tempo, o eurocentrismo da projeção fica claro ao repararmos que a Europa além de estar no centro do mapa, e tem sua área representada bem maior do que realmente é (cerca de dez milhões de $\mathrm{km}^{2}$ ), com praticamente a mesma área da América do Sul (cerca de 18 milhões de km²).

Tendo nossas referências da África - dadas pela mídia, internet, e mesmo os mapas que são utilizados no sistema educacional - constantemente representando o continente como um local selvagem, com uma paisagem constante de savanas e safaris habitados por crianças famintas e tribos exóticas dizimados pelo HIV/AIDS, conflitos étnicos e raciais, é compreensível que mesmo estudantes de graduação de Relações Internacionais tenham uma imagem simplista e muitas vezes marcada por concepções errôneas acerca do continente. 
20 | InterAção

Em palestra feita em julho de 2009 intitulada “O Perigo de uma única história"3, Chimamanda Adichie, escritora nigeriana, narra que ouviu de um professor, enquanto estudava nos Estados Unidos, que o romance que escrevera não era "autenticamente africano", pois as personagens eram muito parecidas com ele, um homem educado de classe média, dirigirem carros e não estarem famintas.

Para compreendermos o que é entendido no Ocidente como "autenticamente africano", o artigo "Como escrever sobre a África” de Binyavanga Wainainasugere:

Sempre use a palavra África, Escuridão
ou Safári no título. Subtítulos podem
incluir 'COngo', 'Nilo', 'Grande', 'Céu',
'Sombra', 'Sol', 'Guerrilhas', 'Primordial'
e 'Tribal'. Nunca tenha a imagem de um
africano bem ajustado na capa de seu
livro, a menos que ele tenha ganhado um
premio Nobel. Armas, costelas
protuberantes, seios nus, você pode usar.
Se usarem vestimentas, que sejam
tradicionais.

${ }^{30}$ título, assim como todos os trechos citados no texto são traduções livres feitas pela autora. 
21 | InterAção

No texto, trate a África como se fosse um só país. Pode ser quente e poeirento, com muitos pastos, hordas de animais e pessoas magras, passando fome, ou quente e úmido, com pessoas de pequena estatura que comem primatas. Não se preocupe com descrições precisas, a África é grande e tem cerca de 900 milhões de pessoas muito ocupadas em passar fome, emigrar, guerrear e morrer para lerem seu livro. Seu leitor não se importa com a diversidade de desertos, florestas, montanhas, savanas e outros ambientes que existem no continente, então mantenha suas descrições românticas e generalistas.

No livro, adote uma postura de conspiração com o leitor, e um tom triste de "eu esperava tanto!". Estabeleça desde o começo o quanto ama a África e não pode viver sem ela, o único lugar que ama. Se você for um homem, se introduza em suas florestas virgens, se for uma mulher trate-a como um homem misterioso que desaparece no pôr-do-sol. A África deve ser alvo de pena, adoração ou dominação, seja qual for o ângulo que você escolher, deixe claro que sem sua importante intervenção e seu livro, a África está condenada.

Seus personagens africanos podem incluir guerreiros nus, servos leais que sempre se comportam como se tivesse sete anos e necessitam de uma mão firme, adivinhos, velhos sábios que vem de tribos nobres e 
vivem em esplendorosa solidão. Também podem ser políticos corruptos, guias de viagem polígamos e ineptos e prostitutas com as quais você dormiu. O homem africano moderno é gordo e trabalha negando vistos de trabalho a ocidentais qualificados que realmente se importam com a África. Ele é inimigo do desenvolvimento e sempre usa seu trabalho no governo para dificultar o estabelecimento de estabelecer ONGs ou Áreas de Conservação. Ele também pode ser um intelectual educado em Oxford que se tornou um político psicopata e é alvo de julgamento por crimes contra a humanidade ou um canibal que gosta de champagne e sua mãe é uma bruxa que domina o país.

Inclua entre as personagens uma africana faminta, que perambula quase nua pelo campo de refugiados e aguarda a benevolência do Ocidente. Ela tem seios flácidos e filhos com moscas nos olhos e barrigas estufadas. Ela é indefesa, não tem passado ou história, pois isto reduz o drama. Também inclua uma mulher boa e maternal, que tem uma grande risada e se importa com seu bem-estar. Seus filhos são delinqüentes e você a chama de Mama.

Todos estes personagens devem gravitar em torno de seu herói melhorando sua imagem. Ele pode ensiná-los, banhá-los, alimentá-los. Ele já viu a morte e carregou muitos bebês. Tal herói deve ser você (se 
23 | InterAção

é um jornalista fazendo reportagem), ou um aristocrata ou celebridade internacional (se for ficção).

Você tem que mostrar que os africanos têm música e ritmo em sua alma, e comem coisas que outros seres humanos não comem. Não mencione arroz, carne ou trigo, cérebro de macaco, cobras e caças. Mostre que o herói come tais comidas, e aprende a gostar delas, pois se importa.

Personagens ocidentais maus podem incluir filhos de Ministros conservadores britânicos, africâneres, trabalhadores do Banco Mundial. Quando tratar de exploração por estrangeiros, mencione os chineses e comerciantes indianos. Culpe o Ocidente pela situação da África, mas não seja muito específico.

Não mencione os africanos dando duro para educar seus filhos. Eles devem ser coloridos e exóticos, mas vazios por dentro, sem diálogos, conflitos ou resoluções em suas histórias, sem profundidade que confunda a sua causa. São tabu cenas domésticas comuns, amor entre africanos (a menos que haja morte), referências a escritores ou intelectuais africanos, menção de crianças freqüentando escolas que não estão sofrendo com ebola ou mutilação genital. 
Descreva em detalhes os seios nus, jovens, velhos, recentemente estuprados, grandes ou pequenos. Também descreva genitais, cadáveres, se possível nus e apodrecendo. Lembre-se, se sua história mostrar as pessoas como miseráveis e sujas, ela será reconhecida como uma história da "África real". Não se sinta mal por isto, você os retrata assim para obter ajuda ocidental para eles! Mas é tabu escrever sobre brancos sofrendo.

Animais, por sua vez, devem ser personagens complexos, com nomes, ambições, desejos e mesmo fala. Eles também têm valores familiares, pode inserir, por exemplo, algo como "Vê como os Leões ensinam seus filhotes?". Elefantes e gorilas são ou feministas ou patriarcas honrados, nunca fale algo negativo sobre eles. Hienas, por sua vez, podem ser caçadas e têm sotaques árabes. Todo africano que mora na floresta é bom, a menos que esteja em conflito com um elefante ou gorila, então ele é mau.

Depois de celebridades ativistas e trabalhadores humanitários, conservacionistas são as pessoas mais importantes na África. Você precisa que eles o convidem para seu rancho ou "área de conservação" de 300 alqueires para entrevistá-los. Uma capa com um conservacionista com cara de herói vende que nem água. Qualquer branco bronzeado, com roupas cáqui e que já teve um animal exótico de estimação é 
25 | InterAção

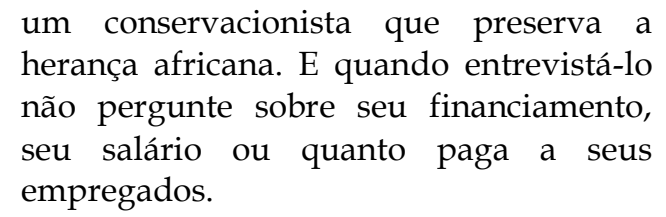

Se você não mencionar a luz na África e seus entardeceres os leitores vão se decepcionar. Sempre há um céu grande, grandes espaços vazios e amplos... e caça! Conte o quanto a flora e fauna a África é superpopulosa, e quando tratar da estadia de seu herói com indígenas, pode mencionar que a população foi dizimada por AIDS ou guerras.

Inclua uma boate chamada Tropicana, onde mercenários, novos-ricos maldosos, prostitutas, guerrilheiros e expatriados passam o tempo. Sempre termine seu livro com Nelson Mandela falando algo sobre arco-íris ou renascimentos, porque você se importa.

Wainaina ilustra uma tradição de contar histórias sobre a África no Ocidente como, nas palavras de Adichie, um lugar de negativos, de diferença, de escuridão.Na mesma palestra acima mencionada, Adichie nos alerta para o fato de que "Uma única história cria estereótipos, e o problema com estereótipos não é que sejam falsos, mas que são incompletos. Eles transformam uma história na única história." 
26 | InterAção

Da mesma forma, os estereótipos que temos acerca da África não são necessariamente falsos, mas incompletos. Há savanas, safaris, crianças e adultos passando fome, infectados por doenças como HIV/AIDS, além de doenças tropicais e auto-imunes entre outras, assim como há em outros locais do mundo. Há tribos exóticas, conflitos racias, étnicos e com outras causas no continente. Mas também há muitas outras dinâmicas, populações e fenômenos no continente, que é composto por 54 Estados, todos diferentes entre si e com diversidade dentro de seus territórios, com populações ativas que vivem seu dia-a-dia, buscando ter uma vida digna e com qualidade de vida, com grande riqueza social e cultural e que desenvolvem políticas relevantes.

\title{
1 MAPEANDO A ÁFRICA NAS NARRATIVAS DAS TEORIAS DE RELAÇÕES INTERNACIONAIS TRADICIONAIS
}

\author{
Tradicionalmente as teorias de Relações \\ Internacionais dedicam espaço marginal aos Estados \\ africanos, assim como a outros Estados pequenos em suas
}


27 | InterAção

formulações explicativas. Da mesma forma, as teorias mainstream $^{4}$ não oferecem as ferramentas mais adequadas para compreender as dinâmicas das relações internacionais africanas, as interações e agência dos Estados africanos (MINILLO, 2012a).

Nas teorias Realistas, por exemplo, as explicações se embasam na agência das grandes potências, sendo reconhecidas no sistema internacional dinâmicas como o Equilíbrio de Poder e band-wagoning, políticas do poder e o direito do mais forte. No entanto, a atuação de Estados africanos como Zimbábue, Líbia e Nigéria, o primeiro sob sanções dasgrandes potências ocidentais atualmente e os outros dois no passado, mostram que nem sempre as grandes potências logram impor suas normas e decisões aos Estados periféricos (MAHMUD, 2001).

As políticas de poder influenciam nas relações internacionais, e certamente a estrutura analítica realista

${ }^{4}$ Considera-se aqui 0 mainstream das Relações Internacionais as perspectivas teóricas (neo)realista, liberal e estruturalista ou marxista, as três participantes do Debate Interparadigmático. Para mais, ver SODUPE, Kepa. La teoría de las Relaciones Internacionales a comienzos del siglo XXI. País Vasco: Universidad del País Vasco, 2003. 
28 | InterAção logra explicar muitos dos fenômenos internacionais. No entanto, o sistema internacional é marcado por diversos tipos de relações, plurais e diversificadas. Algumas delas terão caráter de rivalidade ou mesmo inimizade, mas isto não é necessário. A natureza das interações entre os Estados depende dos papéis com os quais eles identificam uns aos outros. Um exemplo são as políticas de solidariedade e reciprocidade embasadas na identidade comum africana e na defesa da soberania dos Estados africanos que marcam as políticas internacionais desenvolvidas no âmbito da Organização da Unidade Africana e, posteriormente, da União Africana.

As análises sistêmicas das Teorias Neorrealistas, cujo maior expoente é Kenneth Waltz, por sua vez, continuam a tradição Realista clássica de enfocar na agência das grandes potências. Nelas, o sistema internacional é estruturado a partir de polos, em torno dos quais se arranjam as unidades mais fracas em termos de capacidades materiais. No entanto, os Estados periféricos são agentes autônomos, e não vítimas, eles desenvolvem agendas próprias e não apenas reagem ás 
29 | InterAção

políticas das grandes potências, e agem apropriando-se ou não, de acordo com seus interesses, das narrativas dominantes.

No entanto, isto não significa que a perspectiva Realista seja totalmente inadequada para analisar as relações internacionais africanas. Um exemplo é a proposta de John F. CLARK (2001), que diferenciando a busca por segurança dos Estados e dos regimes instalados, traz a tona uma nova dimensão de busca por poder que é recorrente nas políticas desenvolvidas por Estados africanos. Os governantes dos Estados pós-coloniais africanos têm como seu maior objetivo - muitas vezes sendo este um requisito para desenvolver outros objetivos, como políticas de Estado - a segurança de seus regimes. Para continuarem no poder, desenvolvem estratégias que explicam padrões de interação e intervenção externa nos países, os laços que mantém com as grandes potências e mesmo políticas domésticas como o patrimonialismo estatal. Assim, com a devida adequação, abrindo mão do enfoque na atuação das grandes potências e voltando-se para as políticas desenvolvidas pelos Estados 
30 | InterAção

africanos é possível se utilizar da perspectiva Realista para analisar as relações internacionais e políticas externas africanas.

As teorias Liberais, em seu substrato, contam com o ideal de transformação, controle e domínio de natureza pelo homem em prol de progresso econômico, social e tecnológico e caracterizam o Estado como um mal necessário, que garante a proteção dos cidadãos mas deve sempre ser controlado para se defender as liberdades individuais da tirania. Tradicionalmente, elas se voltam para a busca pela Paz e a cooperação por meio do livre comércio, a interdependência, a democracia, o direito internacional, o cosmopolitismo e a institucionalização (NOGUEIRA, J.P.; MESSARI, N., 2005).

Não sendo exemplos de sucesso na implementação de democracias liberais, ou casos ilustrativos de como a expansão do livre comércio internacional leva ao estabelecimento da paz, os Estados africanos são, na maioria das vezes, ignorados pelas teorias liberais (NKIWANE, 2001). No entanto, existem democracias africanas e mesmo levandose em conta os casos de Estados não democráticos, poderiam 
31 | InterAção

ser conseguidos avanços no refinamento do paradigma liberal a partir do estudo os casos de insucesso na implantação de instituições democráticas, pois podem demonstrar as falhas do paradigma liberal e indicar a caminhos para sua reformulação.

Embora Karl Marx não tenha escrito teorias de Relações Internacionais, enfocando nas lutas de classes e nas dinâmicas do capitalismo mundial, o campo de estudos das Relações Internacionais conta com estudos desenvolvidos em perspectivas que emergiram a partir do marxismo, as teorias estruturalistas, da dependência ou marxistas. Tais teorias situam o capitalismo como uma força histórica generalizante de alcance global, que mesmo marcado por contradições se expandiu em escala global com a civilização moderna. Immanuel Wallerstein propõe que o capitalismo criou um sistema-mundo dividido entre Estados desiguais, uns compondo um centro desenvolvido especializado em atividades econômicas intensivas em capital, sofisticadas tecnologicamente e que agregam mais valor e outros compondo a periferia, especializada na produção de bens 
32 | InterAção

primários de baixo valor agregado e intensivas em mão de obra, economias pouco diversificadas e dependentes de exportação de produto primário cujo preço é determinado pelo centro comprador e uma semiperiferia, que desempenha um papel intermediário, combinando aspectos do centro e da periferia (NOGUEIRA, J.P.; MESSARI, N., 2005).

Tais teorias são as mais utilizadas para as análises voltadas aos Estados africanos, explicando o subdesenvolvimento do continente como uma característica estrutural, pois a África seria parte da periferia do sistema. No entanto, segundo DUNN (2001), tal visão é muito generalista, e não explica as diferenças entre os casos de sucesso e insucesso, os diferentes estágios de desenvolvimento dos diferentes Estados e as diferentes políticas de desenvolvimento adotadas pelos Estados. Além disso, adotando o viés desenvolvimentista, toma-se como dado o ideal dos Estados em desenvolvimento "alcançarem" o ocidente, não reconhecendo que podem haver outros objetivos de desenvolvimento que transcendam o projeto de 
33 | InterAção

desenvolvimento ocidental, tido por alguns autores como fracassado.

Percebe-se que nas três visões de mundo tradicionais das Teorias de Relações Internacionais a África está presente sempre como o outro. Ela é parte da periferia do centro, é o pequeno Estado no qual as grandes potências agem e não tem autonomia ou agência própria, um ator reativo. Em resumo, a África está sempre presente como o outro negativo e incompleto que reforça a construção mítica do Ocidente como o padrão do que é normal para um Estado. Esta forma de ver as relações internacionais garante voz e autoridade ao Ocidente e deixa a África e os atores de relações internacionais africanos sem voz. Isto se insere em um processo de construção de significados no campo das Relações Internacionais. 
34 | InterAção

\section{NARRATIVAS E A CONSTRUÇÃO DE SIGNIFICADOS NAS RELAÇÕES INTERNACIONAIS}

Segundo Derrida (apud NOGUEIRA, J.P.; MESSARI, N., 2005), a realidade pode ser entendida como um texto, sendo criada por práticas discursivas que criam sistemas de significados e valores que orientam a ação política. Os significados se constróem por meio de processos de diferenciação, de dicotomias hierarquizadas. Tais dicotomias são estabelecidas a partir de dois elementos, um elemento sempre sendo a visão negativa, corrupta e indesejável e o outro caracterizando o que é bom, correto e desejável, cuja noção positiva que se consolida em oposição ao primeiro elemento. São exemplos as dicotomias bem/mal, presença/ausência, vida/morte, desenvolvido/subdesenvolvido.

As teorias de Relações Internacionais e todo o campo de estudos são tradicionalmente dominados por visões europeias e norte-americanas, e suas visões mainstream não explicam as relações internacionais africanas e as 
35 | InterAção

marginalizam, reforçando por meio desta prática a centralidade e normalidade do mundo ocidental para as relações internacionais.

Isto ocorre pois nas Relações Internacionais, assim como em outras esferas do conhecimento, narrativas são fonte de autenticidade e autoridade. Existem narrativas hegemônicas, que têm maior influência do que outras, e narrativas alternativas, que ainda que não tenham a projeção de narrativas e discursos hegemônicos, também são legítimas, e com seu discurso legitimam histórias diferentes daquelas dominantes. Divergentes entre si, as narrativas não são necessariamente falsas ou verdadeiras, elas apontam e enfatizam aspectos específicos da realidade. Diferentemente da complexidade da realidade, as narrativas e discursos são incompletos, apontam para uma dimensão da realidade. Narrativas diferenciadas podem se complementar ou serem incoerentes entre si e, com suas ênfases diferenciadas, são utilizadas estrategicamente, pois 
36 | InterAção

ponto de partida de uma estratégia
oposta O discurso veicula e produz
poder; reforça-o, mas também mina,
expõe, debilita e permite barrá-lo. (...) Os
discursos são elementos ou blocos táticos
no campo das correlações de força;
podem existir discursos diferentes e
mesmo contraditórios dentro de uma
mesma estratégia
(FOUCAULT,

Assim, fica claro como narrativas têm uma relação dinâmica com o poder: elas são influenciadas pelo poder e podem ser fontes de poder ${ }^{5}$. Reconhecendo a relação dinâmica que existe entre poder e conhecimento, passamos a desconfiar da universalidade das meta-narrativas modernas, como é o discurso científico e suas noções de verdade. Principalmente nas ciências sociais, nas quais o próprio sujeito de pesquisa, um ser humano, também é objeto da pesquisa, o conhecimento produzido na mente de cientistas e filósofos não é produzido em condições de abstração e

${ }^{5}$ Similarmente, não há uma hierarquia fixa estabelecida entre os valores que permeiam as relações e dinâmicas políticas características do sistema internacional. Assim, valores como soberania, auto-determinação, direitos humanos, governança e democracia, que embasam as expectativas, objetivos e estratégias dos atores, são utilizados estrategicamente por eles em seus discursos (por vezes contraditórios) de acordo com seus interesses. 
37 | InterAção

objetividade. Como todo conhecimento, as verdades científicas são produzidas dentro de regimes de poder.

As estruturas de pensamento dominantes nas Relações Internacionais, assim como em outras Ciências Humanas, não são naturais, as melhores ou as únicas formas de ver o mundo. Elas são aquelas autorizadas pelo discurso dominante, isto é, elas reproduzem as relações de poder existentes, as quais agem disciplinando o que será reconhecido como conhecimento ou temas legítimos a comporem a agenda de pesquisa do campo de estudos. Não é coincidência que os discursos e agendas predominantes nas Relações Internacionais sejam de origem ocidental, predominantemente desenvolvidos por Estados Unidos e Reino Unido, Estados que dominaram o cenário das relações internacionis nos últimos séculos. As premissas e objetivos de pesquisa dominantes no campo das Relações Internacionais, muitas vezes tidos como lógicos e naturais, não o são, sendo enviesados por uma visão de mundo ocidental.

Alguns pressupostos considerados naturais nas Relações Internacionais - como a separação entre o 
38 | InterAção

internacional anárquico e o doméstico, ou mesmo a soberania estatal - se mostram, ao exame mais detalhado, serem mitos do campo de estudos (NOGUEIRA, J.P.; MESSARI, N., 2005). Um exemplo disso é o Estado, unidade primária das análises de Relações Internacionais. O ideal de Estado-nação moderno é uma estrutura política independente com autoridade e poder suficientes para governar um território definido e sua população (CLAPHAM, 1987). No entanto, muitas vezes, estes componentes não são reconhecidos nos Estados africanos, que são caracterizados como deficientes e dependentes (DUNN, 2001).

As narrativas que caracterizam os Estados africanos desta forma não contribuem para que eles sejam reconhecidos no ideal de Estado, mas reforçam com o seu exemplo negativo a normalidade do Estado ocidental. É como antípoda do mundo desenvolvido que os Estados africanos se situam nas narrativas mainstream de Relações Internacionais, legitimando o modelo tradicional de Estado Westfaliano ao se contraporem a ele, como exemplos de Estados fracos, não consolidados, estruturalmente falhos e com uma soberania 
39 | InterAção

questionável. Nas palavras de Boaventura de Souza SANTOS (2007: 76), “a negação de uma parte da humanidade é sacrificial, na medida em que constitui a condição para que a outra parte da humanidade se afirme como universal".

Além disso, estes Estados não são vistos como fontes de políticas significativas ou discussões sérias de política internacionais, sendo tomados por conflitos e cenários de catástrofes humanitárias (DUNN, 2001).Um exemplo disto é a discussão a respeito da soberania dos Estados. Segundo JACKSON e ROSBERG (1986), os Estados pós-coloniais, nos quais podemos incluir os Estados africanos, existem graças a seu reconhecimento pela comunidade internacional. Isto é, tais Estados são soberanos primordialmente por serem reconhecidos como Estados e não por terem um aparato estatal consolidado. Tal visão desconsidera as lutas por independência e os esforços de desenvolvimento de Estados em tais territórios pelos locais e reconhe a independência de antigas colônias europeias na África e Ásia como fruto da expansão do direito internacional e da falta de legitimidade do colonialismo frente a valores (ocidentais) de soberania e 
40 | InterAção

auto-determinação, isto é, um processo fruto da agência e de interesses ocidentais.

Esta visão qualifica, indiretamente, os Estados póscoloniais como observadores passivos, espectadores das política internacional que recebem e reagem às políticas das grandes potências e assim, exercem pouca influência no cenário internacional. É claro que o reconhecimento internacional tem um papel importante na consolidação dos Estados, mas isto não implica que os Estados pós-coloniais sejam passivos. Pelo contrário, como CLAPHAM (1996) demonstra, após a descolonização,os Estados africanos desenvolviam suas políticas externas estrategicamente para obterem omáximo de vantagem a partir de seus relacionamentos com as grandes potências no ambiente internacional de Guerra Fria.

Mesmo contando com poucos recursos materiais, os Estados africanos desenvolvem outras formas de ação para garantirem seus interesses. Por exemplo, quando o Ocidente passou a criticar as políticas do governo de Robert Mugabe no Zimbábue e direcionar sanções contra a elite governante 
41 | InterAção

do país, o líder garantiu o apoio de outros Estados africanos e a continuidade de seu regime mobilizando estrategicamente, com seu discurso anti-imperialista e anti-ocidental, a solidariedade dos Estados africanos. Neste caso, o discurso do líder se mostrou uma fonte de poder em suas relações internacionais para impedir que seu Estado se tornasse um pária como o ocidente o caracterizava em um caso que denota uma política externa ativa e criativa(MINILLO, 2012b).

Também podemos identificar no argumento de Jackson e Rosberg a ideia de que, por já terem o reconhecimento internacional de sua soberania, consolidar as instituições de Estado não teria sido necessário a estes Estados como foi para os Estados Westfalianos europeus, ditos "normais". No entanto, podemos usar o estudo de KRASNER (1999) que, a partir de exemplos históricos, demonstra que Estados soberanos Westfalianos sempre conviveram com organizações políticas não-estatais, as quais eram legitimamente aceitas no sistema internacional. Não existindo uma hierarquia estabelecida entre os valores que permeiam o sistema internacional, a soberania dos Estados 
42 | InterAção

foi e ainda é constantemente violada em nome de outros princípios e o reconhecimento de um Estado como soberano e igual por outros Estados é algo mutável, sujeito à sua performatividade.

Paralelamente à existência do mito do Estado-nação, ideal imutável, ocorre um constante processo de constituição dos sujeitos e dos padrões de normalidade e anormalidade que compõe uma espécie de cultura internacional, composta por narrativas diferentes e por vezes divergentes que influenciam as escolhas políticas dos Estados, moldam suas expectativas, valores e comportamento em um processo dinâmico influenciado pela agência dos atores, uns mais que outros de acordo com sua projeção de poder (GELDENHUYS, 2004). Assim são determinadas as narrativas "normais" e "divergentes", sejam elas normas, regras especificadas na forma de leis, convenções ou acordos informais, padrões de comportamento apropriados, em um processo contínuo de determinação e reificação do que caracteriza comportamentos a serem considerados normais ou desviantes, e neste processo o papel da África vem sendo 
43 | InterAção

restrito a ser o diferente e incompleto em oposição ao qual o padrão normal do Estado-nação moderno ocidental se legitima.

\section{CONSIDERAÇÕES FINAIS}

As narrativas que permeiam as relações internacionais são influenciadas por e podem influenciar na distribuição de poder internacional (MINILLO, 2011). Da mesma forma, as narrativas que permeiam as teorias de Relações Internacionais também são afetadas e podem determinar a relação entre este campo do conhecimento e relações de poder. Existem múltiplos discursos acerca do Estado no âmbito da política internacional e no do estudo acadêmico das relações internacionais, que correspondem a visões de mundo e interesses diferentes. Reconhecendo esta diversidade, e a incompletude inerente a cada narrativa, é saudável promover um referencial teórico pluralista nas relações internacionais (MINILLO, 2012a). Além disso, é interessante dar um passo atrás quanto à premissa de 
44 | InterAção

objetividade das Relações Internacionais, reconhecendo a existência de um pluralismo epistemológico, que dê espaço à diversidade de narrativas existentes acerca do que constitui a realidade estudada neste campo de estudos.

É preciso que passemos a reconhecer a existência de outras narrativas das Relações Internacionais, e passemos a contar suas versões, indo além do ideal Ocidental de Estado. Incompletas por natureza, as diversas narrativas constituem a realidade como a conhecemos de forma também incompleta e podem criar preconceitos e ilusões, afastando-nos da realidade levando-nos em direção a um mundo de silogismos e retórica.

Narrativas também empoderar e, ao incluir narrativas alternativas no mesmo patamar daquelas dominantes abrimos espaço para novos fatores serem considerados, como a agência de Estados pós-coloniais, em desenvolvimento, pequenos, fracos, como políticas internacionais relevantes. Assim nos aproximamos de elementos da realidade que tradicionalmente são marginalizados e invisibilizados e podemos ter uma 
45 | InterAção

compreensão mais ampla da realidade internacional melhorando nosso entendimento e, ao mesmo tempo, cumprir uma função emancipatória, dando espaço de destaque àqueles que tradicionalmente são objetos silenciados, reconhecendo-os como atores ativos, agentes de realidades relevantes, compreensíveis e viáveis.

Como membros da periferia do sistema estudando política internacional e o Estado moderno, nas palavras de QUIJANO (2005),

\begin{abstract}
todos fomos conduzidos, sabendo ou não, querendo ou não, a ver e aceitar aquela imagem como nossa e como pertencente unicamente a nós. Dessa maneira seguimos sendo o que não somos. E como resultado não podemos nunca identificar nossos verdadeiros problemas, muito menos resolvê-los, a não ser de uma maneira parcial e distorcida.
\end{abstract}

Isto devido a um eurocentrismo que permeia a epistemologia do mainstream das Relações Internacionais, um espelho que distorce ao refletir nossa realidade (QUIJANO, 2005). Para chegarmos a lentes que não distorçam o que vemos, é interessante, como propõe Boaventura de Souza 
46 | InterAção

SANTOS (1995), “Uma epistemologia do Sul” que se "assenta em três orientações: aprender que existe o Sul; aprender a ir para o Sul; aprender a partir do Sul e com o Sul.

Não se propõe que esta seja a única narrativa das Relações Internacionais. Trazendo a África ao centro dos debates teóricos, como fonte de explicações aplicáveis aos fenômenos internacionais juntamente com o mainstream do campo de estudos podemos repensar as Relações Internacionais reavaliando conceitos consolidados e reificados, rever a aplicabilidade do mainstream teórico, refinando o campo de estudos e mesmo nossa forma de ver o mundo.

\section{REFERÊNCIAS}

ADICHIE, Chimamanda. "O Perigo de uma única história". Palestra de julho de 2009. Disponível em $<$ http://www.ted.com/talks/lang/ptbr/chimamanda_adichie_the_danger_of_a_single_story.html $>$, acessado em 16/12/2013. 
47 | InterAção

CLAPHAM, Christopher. "Review Article: Africa's

International Relations". African Affairs, 86(345): 111-116. 1987

Africa and the International System: The Politics

of State Survival.Cambridge, Cambridge University Press.

1996.

CLARK, John F. "Realism, Neo-Realism and Africa's

International Relations in the Post Cold War Era". In: DUNN, Kevin C.; SHAW, Timothy M. (Eds.). Africa's challenge to International Relations Theory. New York, Palgrave Macmillan, 2001, p. 85-102.

DUNN, Kevin C. "Introduction: Africa and International relations Theory". In: DUNN, Kevin C.; SHAW, Timothy M. (Eds.). Africa's challenge to International Relations Theory. New York, Palgrave Macmillan, 2001, p. 1-10.

FOUCAULT, M. História da sexualidade I: A vontade de saber. Rio de Janeiro, Edições Graal. 1988.

GELDENHUYS, D. Deviant Conduct in World Politics. Nova Iorque: Palgrave Macmillan. 2004. p. 17

JACKSON, Robert H.; ROSBERG, Carl G. “Sovereignty and Underdevelopment: Juridical Statehood in the African Crisis". J. of Modern African Studies, 24(1), 1986, p 1-31.

KRASNER, Stephen D. Sovereignty: Organized Hypocrisy. Princeton, Princeton University Press. 1999.

MAHMUD, Sakah. “Controlling African States' Behavior: International Relations Theory and International Sanctions 
48 | InterAção

against Libya and Nigeria". In: DUNN, Kevin C.; SHAW, Timothy M. (Eds.). Africa's challenge to International Relations Theory. New York, Palgrave Macmillan, 2001, p. 129-145.

MINILLO, Xaman Korai. Enfrentando o norte - discursos e ideologia como fontes de poder para o regime de Robert Mugabe. Dissertaçãod e Mestrado. Brasília: UNB, 2011. Disponível em <http://repositorio.unb.br/bitstream/10482/9800/1/2011_X amanKoraiPinheiroMinillo.pdf $>$. Acessado em 10 de Janeiro, 2014.

A importância do estudo das Relações Internacionais africanas para o campo das Relações Internacionais. Monções: Revista de Relações Internacionais da UFGD, v. 1, p. 156-181, 2012a.

Solidariedade, Discursos e Ideologia como fontes de poder nas Relações Internacionais Africanas: o caso de Robert Mugabe. Século XXI : revista de relações internacionais / Escola Superior de Propaganda e Marketing do Rio Grande do Sul., v. 3, p. 41-58, 2012b.

NKIWANE, Tandeka. “The End of History? African Challenges to Liberalism in International Relations"In: DUNN, Kevin C.; SHAW, Timothy M. (Eds.). Africa's challenge to International Relations Theory. New York, Palgrave Macmillan, 2001, p. 103-111.

NOGUEIRA, J. P.; MESSARI, N. Teoria das Relações Internacionais - Correntes e Debates. Rio de Janeiro, Elsevier. 2005. 
49 | InterAção

QUIJANO, Anibal. “Colonialidade do poder, eurocentrismo e América Latina". In:A colonialidade do saber: eurocentrismo e ciências sociais. Perspectivas latino-americanas. Edgardo Lander (org). Colección Sur Sur, CLACSO, Ciudad Autónoma de Buenos Aires, Argentina. setembro 2005. pp.227-278.

SANTOS, Boaventura de Sousa. "Para além do pensamento abissal: das linhas globais a uma ecologia de saberes". Novos estud. - CEBRAP, São Paulo, n. 79, Nov. 2007 . Disponível em<http:/ / www.scielo.br/scielo.php?script=sci_arttext\&pid $=$ S0101-33002007000300004\&lng $=$ en\&nrm=iso $>$. Acessado em 10 de Janeiro, 2014.

Toward a New Common Sense: Law, Science and Politics in the Paradigmatic Transition. New York: Routledge. 1995.

SODUPE, Kepa. La teoría de las Relaciones Internacionales a comienzos del siglo XXI. País Vasco: Universidad del País Vasco, 2003.

WAINAINA, B. "How to Write About Africa", Granta, Edição 92, 2005. Disponível em <http:/ / www.granta.com/Archive/92/How-to-Writeabout-Africa/Page-1>, acessado em 16/12/2013. 